then, like suicide, the second attempt becomes much more likely.

The College could encourage this activity by publishing an Annual Bumper Book of Coarse Psychiatric Research which would contain selected synopses of these works. What a joy to read short accounts of all ideas pursued by our bright young doctors!

The only good research is coarse research. 'Good' research is the mopping up of the successful ideas generated by coarse research. The encouragement of original thinking is a prime educational responsibility of our College.

Warlingham Park Hospital

C. McDonald

Warlingham, Surrey CR3 9YR

\section{Support and stay}

DeAR SIRS

The interesting article by Whitby and his colleagues 'Support and stay: an innovative community service for the elderly confused' (Psychiatric Bulletin, December 1990, 14, 708-710) illustrates marked differences in the balance between health and social services provision for the demented elderly across the country. In our own health district the sort of activities described by Whitby are entirely the province of social services: now the subject of a pilot project involving budget-holding case managers who can arrange an even more flexible package of care than that provided by the "Sas" service reported by Whitby. My main question is this: in what way does a psychogeriatric service differ from a social service? There is nothing in Whitby's article that suggests that the "Sas" service should not be available to all clients with a dementia, rather than only those referred to a specialist service.

United Medical and Dental School

A. J. D. Macdonald

Hither Green Hospital

London SE13 6RU

\section{Personal experience with clozapine}

DeAR SIRS

Clozapine is a dibenzodiazepine derivative. In 1975, granulocytopaenia developed in 16 patients taking clozapine in Finland. Subsequently 13 of these developed agranulocytosis and eight died from secondary infection (Griffith \& Saameli, 1975). A multi-centre trial in the USA involving 319 patients (Kane $e t$ al, 1988) and a study in Germany involving 387 patients (Naber et al, 1989) produced only one death; a causal relationship between clozapine and the fatality could not be excluded but was not probable. The present risk rate of white cell problems has been summarised at $1-2 \%$ which should be taken with a comparable risk of $0.01-0.1 \%$ of agranulocytosis with phenothiazines.

The current prescribing regulations in the UK demand weekly white cell counts for 18 weeks, which is the high risk period, and fortnightly white cell counts thereafter. Worldwide experience suggests that if this is strictly adhered to, and tablets are supplied only on receipt of normal white cell results, then all cases of agranulocytopaenia will recover solely on rapid cessation of the drug.

Clozapine was introduced in the spring of 1990 to the UK and marketed to consultant psychiatrists in NHS practice. Currently only $10 \%$ have used it and most have given it to only one or two patients. There are only about 500 patients who have experienced the drug in this country. Because of the above diffculties, Sandoz UK have suggested that the drug is used for schizophrenic patients who are resistant to conventional antipsychotic therapy or who do not tolerate these drugs.

I have prescribed clozapine for a total of 13 patients for a maximum of eight months and all but one are still on the drug. In two cases I had to discontinue the drug due to lack of response and in one case the patient refused to take the drug due to his paranoid state. All three of these cases were recommenced with some improvement. The one case that was not recommenced suffered a severe extra-pyramidal reaction as he had done with conventional drugs but recovered with anti-parkinson drugs and discontinuation of the clozapine. There were no cases of agranulocytopaenia that were serious enough to cause a 'red alert' and stop the drug but several cases triggered an 'amber alert' occasionally due to a damaged sample.

There were eight males and five females, all caucasian, and the age range was from $20-52$. Seven out of the eight males had spent time on an interim secure unit. The dose range of clozapine was from $300-900 \cdot \mathrm{mg}$ daily with some on a single nightly dose and others on split dosage. All the patients had been on oral and depot phenothiazines and most had been on at least three different depots in doses up to $1000 \mathrm{mg}$ fluphenazine decanoate weekly or equivalent. The duration of illness ranged from two to 17 years and all but three had been admitted to hospital before the start of the clozapine.

The side effects seen most commonly were hypersalivation and morning drowsiness, but one case suffered tachycardia and three cases had a total of five grand mal fits. Two of these were being withdrawn simultaneously from benzodiazepines. Most of the patients were left on anti-parkinson medication and two were left on lithium carbonate but other anti-psychotic drugs were used in only three patients. 